\title{
The Objective Structured Clinical Exam (OSCE): A Qualitative Study evaluating Nursing Student ${ }^{\text {ee }}$ Experience
}

\author{
Afaf AbdAlla ${ }^{1}$, Khalid Mohammed ${ }^{2}$ \\ ${ }^{1}$ Obstetrics and Gynecological Nursing Dept., Faculty of Nursing, Alneelain University, Sudan
}

\begin{abstract}
This study evaluates the clinical competences and decision making of students before they enter the clinical setting. Objective Structured Clinical Examination (OSCE) becomes an integral evaluation method in nursing fields. Because the OSCE is a new experience for most students, it is important as educators, that we explore this assessment from perspective of the student. A descriptive design was utilized for collecting the data that are necessary to answer the research question. The sample consisted of 60 students who finished the $1^{\text {st }}$ year theortical and clinical teaching course of Basic Nursing and were evaluated by OSCE. Data was collected through semi-structured interviews with students. Analysis revealed three main themes: quality of instruction and organization of objective structured clinical examination, perception about the formal of OSCE, and Evaluation of quality of OSCE performance. The majority of the students appreciate the format of OSCE. The study highlighted that there are more need for Students' orientation period about OSCE to be planned in a form of a written check list of what would be expected of them and what they expect, and training sessions on OSCE procedure. and relieving their emotional stress during implementation of OSCE. The implementation of OSCE at Faculty of Nursing, Alneelain University was a useful experience for students, and was considered a valuable and worthy for further enhancement. Which need careful consideration by academic faculty developing this type of evaluation.
\end{abstract}

Keywords: Objective Structured Clinical Examination, Nursing students, Clinical setting, Perception, decision making.

\section{Introduction}

Objective structured clinical examination (OSCE). Is a multi-system examination using real or simulated patients to evaluate clinical skills, attitudes and cognitive abilities. It demonstrated reliability and validity for assessing clinical performance [1].

Since its development in the 1970s by Dr. Ronald Harden, the OSCE has gotten momentum for clinical assessment to evaluate the nursing student's clinical competencies. Objective Structured Clinical Examination (OSCE) is now established as one of the most valid, reliable and effective tests to measure cognitive, interpersonal communication,

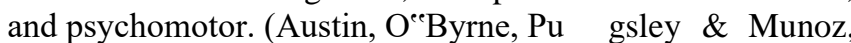
2003; Rentschler, et al., 2007), and is considered as a fair and comprehensive means of evaluation (Al Omari \& Shawagfa, 2010). To perform these skills, there is a great need for the presence of a simulated clinical or patient care environment as appear in Nulty, Mitchell, Jeffrey, Henderson and Groves (2011) study [2].

Many study outcomes concluded that the OSCE was recommended as a beneficial and effective tool for evaluating nursing students' clinical performance [3].

Before there is a traditional tool for assessing medical students has basically consisted of a written exam (essay type, multiple choice, and short-answer type questions), bedside viva and clinical case presentation. These have depended and interpret the Milleres pyramid o f competency "knows" and "knows how" to "shows how". However, this method has exhibited a lot of criticism over the years because of their inability to evaluate the top levels of the pyramid of competency. OSCEs have been modified in numerous ways since their inception until reaching the reliability, manner [4]The OSCE in addition to it is the property of summative assessment also used in formative assessment that provided by 2007; Brosnan et al, 2006; Alinier, 2003). Beckham (2013) in their study and concludes OSCEs can identify students who are weak in performing clinical skills early on in their program. With a raised awareness of this, and the help of tutors, mentors and lecturers, students can be directed to extra sessions, resources and assistance in practice [5].

Byrne and Smyth (2008) agree that OSCE as an approach to students ${ }^{c e}$ assessment in which aspects of clinical

competence are evaluated in a comprehen- sive, consistent and structured manner, with close attention to the objectivity of the process [6]

Students go around the complete circuit of stations, and keep on doing the tasks of each of the placard. All students move from one station to another in the same sequence. The stations are categorized as ,procedure station ${ }^{\text {ce }}$ or ,question station ${ }^{e e}$. Procedure stations are observed by the examiner while question stations are unobserved (only a written answer is desired) [4].All students are assessed using exactly the same stations with the same marking scheme to make the assessment of clinical skills more objective rather than subjective (Rushforth, 2007) [7].

Procedure station and a questionable station can also be used together. In the original description of OSCE by Harden, every Procedure station was followed by a Question station. They have two advantages: (a) different domains of learning can be assessed by them; and (b) the effect of cueing is minimized. A rest station for every 30-40 minutes into the exam, justified to give a break to the students, the observers and the patients. They also allow time to substitute 


\section{International Journal of Science and Research (IJSR) \\ ISSN (Online): 2319-7064 \\ Index Copernicus Value (2013): 6.14 | Impact Factor (2014): 5.611}

patients at a clinical situation, or to complete the written left over task from the previous stations $[8,9]$.

OSCE students were more stressed than the traditional method, Most of the students

Considered time limitation is one of the important factors in producing stress in OSCE method [10].

Objective structured clinical examinations (OSCEs) are an effective assessment strategy for assessing clinical skills (Alinier et al., 2006) and for highlighting curriculum problem areas (Major, 2005).

In light of these views, an OSCE was used to assess first year students ${ }^{\text {ee }}$ clinical competence following completion of a nursing module and students ${ }^{\text {ee }}$ first clinical placement. This paper presents nurse students ${ }^{\text {ee }}$ experiences and perspectives of clinical competence using an OSCE and addresses the challenges associated with the assessment. It is anticipated that the findings will produce strong evidence for utilizing OSCEs as an assessment strategy in an undergraduate nursing program and provide theoretical guidance for nurse educators interested in implementing OSCE [11].

\section{Aim of the Study}

The aim of the study was to assess the1st year nursing Student's Perception about the Objective Structured Clinical Examination (OSCE) in the Basic Nursing Course.

\section{Research Questions}

1. What are the perceptive views of the nursing students about the organization, format and quality of the OSCE?

\section{Methods}

This study was carried out by faculty of nursing in the first year BSc students Part-II Basic Nursing examination. A convenient sample of 60 of undergraduate nursing students was involved in this study.

\section{Tools of data collection}

Pierre et al(2004) OSCE evaluation questionnaire was adapted in this study. For the purpose of this study, only 13 items of the Pierre et al questionnaire were used, and a few items were slightly modified to give a clear meaning.

The questionnaire used in the current study consists of three main sections:

- Section one assesses nursing students' evaluation of the OSCE attributes, Students were asked to rate their responses on a three point scale ranging; 'disagree', 'neutral' and 'agree'.

- Section two looks at nursing students' evaluation of the format of OSCE.

- Section three investigates nursing students' evaluation of the OSCE performance.

An ethical approval was obtained from the Faculty of Nursing Ethics Committee. All students were informed that their participation was voluntary, and that not taking part in this study would not affect them in any way and Oral consent was obtained from the students.

\section{Data Analysis}

Data were analyzed using the Statistical Package for Social Science (SPSS version 20). The obtained data were coded, analyzed and tabulated. Descriptive analysis was performed in this study, including frequencies and percentage.

\section{Results}

The results obtained from the 60 first year nursing students, presented in Tables (1, 2, and 3). The response rate of the students was $100 \%$.

Table (1): represents nursing students' evaluation of OSCE quality and organization. The results of the questionnaire revealed that the majority of students provided positive feedback about the OSCE quality and organization. They agreed that the OSCE was fair (70\%), Most students felt that OSCE stations were well structured and sequenced ((75.0 $\%$,), still a considerable percentage of students felt that the exam was very stressful (70.0\%) and highlighted more objectivity (90.0\%).

Table (2): points out to nursing students' evaluation of the quality of OSCE performance. The majority of students reported that they were reported hat time of each station and number is adequate $(60.0 \% \$ 86.6 \%)$ respectively. More than half they reported that no revision was done before the examination. More than two third reported that OSCE provide the essential skills procedure.

Table3: OSCE provided them with more learning opportunities Performance (81.7\%) and reflected those which were taught. Most students (63.3\%) reported that the stations were organized in sequence and logical way. More than $89 \%$ of students in both groups agreed that the instructions on the exam were clear and give them the opportunity to learn (81.7\%).

Table1: Number and percent distribution of students according to their evaluation of the quality of OSCE attributes.

\begin{tabular}{|c|c|c|c|c|c|c|}
\hline \multirow{2}{*}{ Variable } & \multicolumn{2}{c|}{ Agree } & \multicolumn{2}{c|}{ Neutral } & \multicolumn{2}{c|}{ Disagree } \\
\cline { 2 - 7 } & Frequency & Percent & Frequency & Percent & Frequency & Percent \\
\hline The OSCE was fair & 42 & $70 \%$ & 9 & $15 \%$ & 9 & $15 \%$ \\
\hline The exam was well structured & 45 & $75 \%$ & 11 & $18.3 \%$ & 4 & $6.7 \%$ \\
\hline In OSCEC exam all the student did the same procedure & 54 & $90 \%$ & 4 & $6.7 \%$ & 2 & $3.3 \%$ \\
\hline OSCEC was very stress full & 42 & $70 \%$ & 12 & $20 \%$ & 6 & $10 \%$ \\
\hline Total & 60 & $100 \%$ & 60 & $100 \%$ & 60 & $100 \%$ \\
\hline
\end{tabular}




\section{International Journal of Science and Research (IJSR) \\ ISSN (Online): 2319-7064}

Index Copernicus Value (2013): 6.14 | Impact Factor (2014): 5.611

Table 2: Number and percent distribution of students according to their OSCE format

\begin{tabular}{|c|c|c|c|c|c|c|}
\hline \multirow{2}{*}{ Variables } & \multicolumn{2}{c|}{ Agree } & \multicolumn{2}{c|}{ Neutral } & \multicolumn{2}{c|}{ Disagree } \\
\cline { 2 - 7 } & Frequency & Percent & Frequency & Percent & Frequency & Percent \\
\hline The time of each station is adequate & 36 & $60 \%$ & 8 & $13.3 \%$ & 16 & $26.7 \%$ \\
\hline The number of OSCEC station is sufficient & 52 & $86.7 \%$ & 4 & $6.7 \%$ & 4 & $6.7 \%$ \\
\hline $\begin{array}{c}\text { The revision done before the examination about different } \\
\text { types of clinical procedure }\end{array}$ & 21 & $35 \%$ & 5 & $8.3 \%$ & 34 & $56.7 \%$ \\
\hline $\begin{array}{c}\text { Are you thinking the OSCEC is provide the measure of } \\
\text { clinical essential skill }\end{array}$ & 42 & $70 \%$ & 9 & $15 \%$ & 9 & $15 \%$ \\
\hline Total & $\mathbf{6 0}$ & $\mathbf{1 0 0} \%$ & $\mathbf{6 0}$ & $\mathbf{1 0 0} \%$ & $\mathbf{6 0}$ & $\mathbf{1 0 0} \%$ \\
\hline
\end{tabular}

Table3: Number and percent distribution of students according to their Evaluation of quality of OSCEC performance

\begin{tabular}{|c|c|c|c|c|c|c|}
\hline \multirow{2}{*}{ Valid } & \multicolumn{2}{|c|}{ Agree } & \multicolumn{2}{c|}{ Neutral } & \multicolumn{2}{c|}{ Disagree } \\
\cline { 2 - 6 } & Frequency & Percent & Frequency & Percent & Frequency & Percent \\
\hline Instruction were clear & 49 & $81.7 \%$ & 4 & $6.7 \%$ & 7 & $11.7 \%$ \\
\hline Sequence of station logical & 38 & $63.3 \%$ & 5 & $8.3 \%$ & 17 & $28.3 \%$ \\
\hline Station reflect those taught & 55 & $91.7 \%$ & 1 & $1.7 \%$ & 4 & $6.7 \%$ \\
\hline Exam provided opportunities to learn & 49 & $81.7 \%$ & 3 & $5 \%$ & 8 & $13.3 \%$ \\
\hline Total & 60 & $100 \%$ & 60 & $100 \%$ & 60 & $100 \%$ \\
\hline
\end{tabular}

\section{Discussion}

Feedback from nursing students suggests that OSCE is an objective tool for evaluating clinical skills. Students perceived OSCE scores as a true measure for the essential clinical skills being evaluated, standardized, and not affected by the student's personality or social relations.[12].

Most students provided positive feedback about the quality of OSCE performance in terms of the clarity of the instructions on the exam, the sequence of OSCE stations, the reflection of the tasks taught and the time at each station. These results are supported by Pierre et al (2004) findings [13].

However, the OSCE was perceived as a stressful experience and intimidating by a considerable percentage of students. This perception could be due to the fact that this was the first time that students exposed to this type of assessment. Hence, it was a new experience for the first level of nursing students which made them feel anxious about it. In future it would be preferable to use the OSCE in the midterm exam as a preparation stage for students before the final OSCE. Findings are similar to the research work reported by Brosnan [14] who mentioned that more than half of the students (52.7\%) agreed that the OSCE was more stressful than a written formal examination. These findings are also consistent with the Major who clarified that the students still graded this method of assessment as stressful. Stressful experience with OSCE was also reported in other studies. Similarly, other studies related students' stress and anxiety to the new experience of going through the OSCE [15].

The results indicated that nearly half of the students considered the organization of the OSCE is very good which is inconsistent with Troncon who mentioned that nearly half of the students (48\%) criticized the organizational aspects of OSCE[16].

However, the high response rate for students, and their positive feedback about OSCE as an evaluation tool for their clinical performance have been pointed.
The Buckingham reported that the main advantage of the OSCE is providing greater objectivity for assessment particularly for junior students. Concerning the disadvantages of OSCE, the present study indicated was required careful planning as the highest proportion (63.3\%). While OSCEs are an effective method of assessing clinical competence, they are costly to execute in terms of manpower, resources and time elements and require careful planning to be successful which is similar to the present study [17].

\section{Conclusion}

The OSCE appears to be a useful and acceptable method for evaluating nursing students' clinical performance because of various positive specifications such as, objectivity and fairness. The implementation of OSCE at Faculty of Nursing, Alneelain University was a useful experience for students, and was regarded a valuable and worthy for further growth and enhancement. Stress could be decreed logically and familiarizing the students with the condition and limitation of the OSCE through practice during the condition.

\section{Recommendations}

1) Students' orientation period about OSCE should be contrived in a shape of a written description of what would be required of them and what they could expect, and training sessions on OSCE procedure. This is really important for familiarizing students with OSCE, reducing their stress and anxiousness, and improving their experience.

2) While this study investigated nursing students' feedback about the OSCE, future research could consider faculty, staff members' experience with the implementation of OSCE.

3) Preparing standardized and approved OSCE stations for each department.

4) A larger study is needed to establish the effectiveness of the OSCE within nurse education programs. An exploration of how successful students transfer into 


\section{International Journal of Science and Research (IJSR) \\ ISSN (Online): 2319-7064 \\ Index Copernicus Value (2013): 6.14 | Impact Factor (2014): 5.611}

clinical practice and to explore the validity and reliability of the OSCE.

\section{Acknowledgement}

We would like to express our deep appreciation to all students who participate in highlighting the clinical learning keys of OSCE in our research.

\section{References}

[1] Mondal R,1 Sarkar S,etal. Clinical Examination (OSCE) and Conventional Examination (CE) As a Formative Evaluation Tool in Pediatrics in Semester Examination for Final MBBS Students.

[2] Bayoumy M. H. and Yousri H. Objective Structured Clinical Examination (OSCE) - Based Assessment in Nursing: Students' and Clinical Instructors' Perception. Journal of American Science, 2012; 8(9) Available http://www.americanscience.org

[3] EL-nemer A, Kandeel N. Using OSCE as an Assessment Tool for Clinical Skills: Nursing Students' Feedback. 2009. Med. J. Cairo Univ., Vol. 77, No. 4, June:

457-464 www.medicaljournalofcairouniversity.com

[4] Gupta P, Dewan P and Singh T. Objective S tructured Clinical Examination (OSCE) Revisited. 2010. Indian Pediatrics (911):47 17,

[5] Liddle C. The Objective Structured Clinical Examination. Nursing Times 110 Online issue Vol. www.nursingtimes.net

[6] KATOWA P. -MUKWATO et al. Implementation of Objective Structured Clinical Examination for Assessing Nursing Students ${ }^{\text {ee }}$ Clinical Competencies: Lessons and Implications* Creative Education.2013;4(10) 48-53 (http://www.scirp.org/journal/ce).

[7] El-Nemer, A., Kandeel, N. Objective structured clinical examination (OSCE): review of literature and implications for nursing education. Nurse Educ. Today 2009; 27: 481-490.

[8] Boursicot K, Roberts T. How to set up an OSCE. Clin Teach 2005; 2: 16-20

[9] South Eastern Europe Health Sciences Journal (SEEHSJ) .2013;3(1)L13-18

[10] Bagheri M 1, SadeghnezhdM, Shaghayee MFallah. The Comparison of Stressors in the Assessment of Basic Clinical Skills with Traditional Method and OSCE in nursing Students. Life Science Journal. 2012;9(4) http://www.lifesciencesite.com

[11]Byrne E, Smyth S. Lecturerse experiences and perspectives of using an objective structured clinical examination. Nurse Education in Practice. 2008, (8): 283-289

[12] Eswi, et al., OSCE in Maternity and Community Health Nursing: Saudi Nursing Student's Perspective. American Journal of Research Communication. 2013; 1(3) www.usa-journals.com

[13]PIERRE R., WIERENGA A., BARTON M., BRANDAY J., et al.: Student evaluation of an OSCE in pediatric at the University of the West Indies, Jamaica. BMC Medical Education. 2004; 4 (22): 1-7,
[14] Brosnan, M.; Evans, W. and Brown, G. Implementing Objective Structured Clinical Examination (OSCE) in nurse registration programmes in a center in Ireland: A utilization focused evaluation. Nurse Education Today. 2006; 26: 115-122.

[15]RYAN S., STEVENSON K. and HASSELL A.: Assessment of clinical nurse specialists in rheumatology using an OSCE. Musculoskeletal Care. 2007.5 (3): 119129, Published Online: 28 Aug

[16] Troncon, l. Clinical skills assessment: limitations to the introduction of an "OSCE" (Objective Structured Clinical Examination) in a traditional Brazilian medical school. Sao Paulo Medical Journal. 2004; 122 (1): 1-9.

[17] Mahmoud GA and Mustafa MF.The Egyptian Nursing Student's Perceptive view about an Objective Structured Clinical Examination (OSCE).Journal of American Science. 2011;7(4) http://www.americanscience.org 